\title{
Self-Regulated Learning and the Understanding of Complex Outcomes
}

\author{
Monique Boekaerts, ${ }^{1}$ Mariel Musso, ${ }^{2,3,4}$ and Eduardo C. Cascallar ${ }^{2,4}$ \\ ${ }^{1}$ Center for the Study of Learning and Instruction, Leiden University, The Netherlands \\ ${ }^{2}$ Centre for Research on Teaching and Training, Katholieke Universiteit Leuven, Belgium \\ ${ }^{3}$ Universidad Argentina de la Empresa, Buenos Aires, Argentina \\ ${ }^{4}$ Assessment Group International, USA/Europe, Brussels, Belgium \\ Correspondence should be addressed to Monique Boekaerts, boekaerts@fsw.leidenuniv.nl
}

Received 29 November 2012; Accepted 29 November 2012

Copyright (C) 2012 Monique Boekaerts et al. This is an open access article distributed under the Creative Commons Attribution License, which permits unrestricted use, distribution, and reproduction in any medium, provided the original work is properly cited.

There is ample evidence that the study of self-regulation and self-regulated learning (SRL) in particular is of significant importance in education and in the understanding of the variables that influence learning. In this context, the role of assessment is central to the current work in the field of self-regulation research, to the conceptualizations derived from empirical work, and to the operationalisation of its concepts in individual and classroom implementations (E. C. Cascallar and M. Boekaerts, 2006).

Self-regulation is a complex construct to define and to operationalise. The various conceptualizations of selfregulation all presuppose a detailed accounting of many different components, each of them represented by a variety of proxy variables which can be measured to establish the appropriate level at which the individual or group in question is functioning or performing. These assessments involve an evaluative process in order to estimate the level of performance, achievement, or functioning, through a consistent methodology that rigorously estimates and scales individual or group results based on predetermined standards or on normative performance data.

In recent years technology has had an enormous impact in improving both the quality and the utility of assessment. New technology-driven infrastructures have contributed to the quality of assessment systems. These technologies, and the conceptual advances they have enabled, have been instrumental in increasing the potential for new feasible designs of instruments, programs, and applications. In the field of SRL, the use of these technologies, new statistical and modeling methodologies, and conceptual advances in the understanding of self-regulated learning, have all contributed to advances that have enriched and also changed this field of study.

There is an extensive literature on SRL and its interactions with several environmental and student characteristics. Although several theoretical models have been developed, different authors have focused on several different dimensions or components. While most of them agree that SRL is a complex and dynamic interaction of cognitive, affective, social, and volitional processes in the service of one's own goals, the field is still lacking a unified perspective on these complex phenomena. Definitions of SRL as a relatively stable individual inclination have been shifting to other definitions of SRL as a complex process in situated learning conditions.

Papers in this special issue share this last perspective considering multiple processes and their interrelations between student and task/context. Six papers contrast different theoretical and empirical frameworks and collectively show how new methodologies can address the complexities of the interactions of the variables involved. These papers either contribute to a better prediction and understanding of learning outcomes, or they focus on new integrative conceptualizations of the field. Thus, the purpose of this special issue is to consider new methodological and conceptual 
developments in the understanding of self-regulated learning in different domains such as: academic success, mathematical performance, and successful professional development.

T. J. Cleary, G. L. Callan and B. J. Zimmerman describe the essential features of a contextualized assessment approach, namely Self-regulated Learning Microanalysis, which encompasses elements of both self-report and event measures. The authors review the most relevant research related to the use of this assessment technique. Moreover, an interesting guide whose specific microanalytic questions used to target self-regulation subprocesses (e.g., goal-setting, strategic planning, etc.) are highlighted, focusing on causal attributions. The authors finalize their paper discussing several educational implications and areas for future research.

Two papers highlight different predictive approaches in educational assessment: one from a more traditional statistical perspective using regression, and the other one applying Artificial Neural Networks (ANN). G. Vanthournout, D. Gijbels, L. Coertjens, V. Donche (Students' persistence and academic success in a first year professional bachelor program: the influence of students' learning strategies and academic motivation) explore whether students' learning strategies and academic motivation predict persistence and academic success in the first year of higher education, discussing their values and limitations. The authors apply traditional statistical methods. The other paper which uses predictive methodologies is entitled "Predicting mathematical performance: the effect of cognitive processes and selfregulation factors", M. Musso, F. Kyndt, E. C. Cascallar and F. Dochy, examine different cognitive patterns and complex relations between basic cognitive variables, motivation, and background variables associated with different levels of mathematical performance using Artificial Neural Networks (ANN). It is with the emergence of new methodologies and technologies, including the use of modeling with predictive systems as done in this paper, that it is now possible to study those complex interaction effects and evaluate their impact with approaches which use a wide range of data or student productions, to estimate student performance without the need of traditional testing (M. Boekaerts \& E. C. Cascallar, 2006). Results demonstrate a more robust method to predict and classify different levels of performance, compared with more traditional methodologies. ANN's advantages and their implications for educational research and intervention programs in educational settings are discussed by the authors.

Two papers invite us to analyse the problem of assessing on-line the processes involved in self-regulated learning. In their paper "Metacognitive strategies and test performance: an experience sampling analysis of students' learning behavior", U. E. Nett, T. Goetz, N. H. Hall and A. C. Frenzel evaluate the use of Experience Sampling Methods, a longitudinal and "in vivo" approach that allows an analysis of the developmental nature of the self-regulated learning process. Despite considerable research on metacognitive strategies, the authors open new and specific questions about the frequency and effectiveness of metacognitive strategy use as evaluated during the actual learning process. Advantages of an in-depth assessment of the most effective metacognitive strategies, comparing the limitations of global measures with the measurement of situation-specific strategy use, are discussed. Moreover, the implications for intervention programs as well as classroom environments are analyzed. The authors point out the necessity of more and better methodological research, as well as the need for additional measures of validity and reliability for data obtained from experiential-sampling methods.

G. Lust, J. Elen, and G. Clarebout present a study which investigates the relation between the students' tool use in a Content Management System and the students' strategy use. Content management systems (CMSs), such as Blackboard and WebCT, provide a rich toolset with a variety of learning support to students, giving students control over the use of these tools. The authors analyze this relationship between the tools provided and the students' strategies using Kmeans cluster analyse, and find different patterns which raise interesting questions with respect to students' tool perceptions and students' calibration abilities.

Z. Kohen and B. Kramarski invite us to analyze, from a teachers perspective, how self-regulated learning processes can be enhanced to an optimum level, and the problem of assessing these processes. The authors present one experimental study in real-time teaching using a digital-video Microteaching environment where the SRL process was measured as an online event during real-time teaching exercises, identifying metacognitive and motivational aspects of the processes. Important implications for practical interventions using reflective support for teachers' self-regulated learning are discussed.

This special issue summarizes recent advances in the explanation, modelling, and prediction of specific performances in specific contexts, considering self-regulation factors, with special emphasis given to the technical and empirical results obtained within the last five years. Together, the 6 papers make an important contribution to our understanding of what SR is, how we can assess it in its entirety, and how we can design intervention programs to promote effective self-regulatory strategies. We hope that the ideas and information presented in this special issue will spur researchers' interest in designing assessment instruments to measure the degree to which students and teachers have acquired and use domain-specific self-regulation strategies. Although a lot still needs to be learned about how best to enhance students' and teachers' self-regulatory strategies, we are convinced that the papers in this special issue will show researchers how new methodologies can be used successfully to address the complexities of the interactions of the many variables involved in self-regulation. In our opinion, it is absolutely essential for the development of a sound knowledge base on SR to use reliable and valid multidimensional assessment tools that can register progress in the use of self-regulatory strategies.

Monique Boekaerts Mariel Musso Eduardo Cascallar 


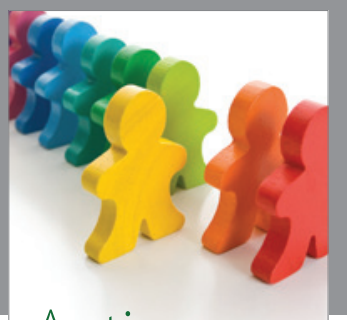

Autism

Research and Treatment
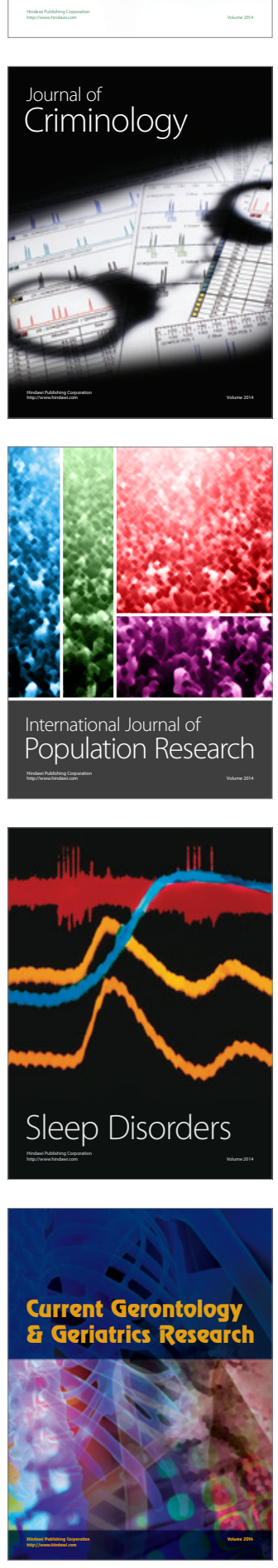
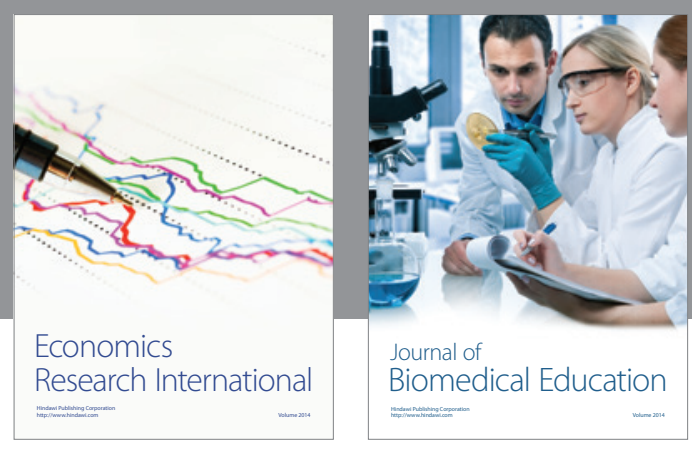

Journal of

Biomedical Education

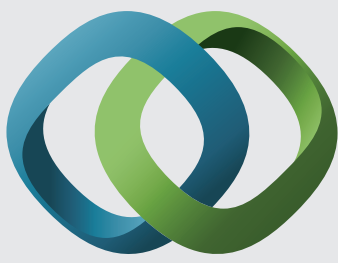

\section{Hindawi}

Submit your manuscripts at

http://www.hindawi.com
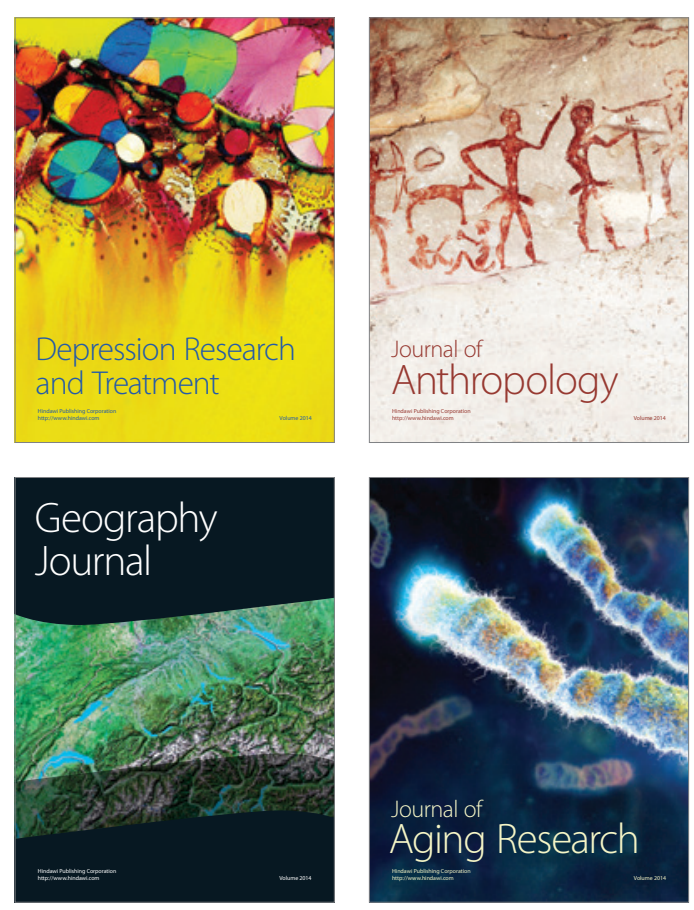

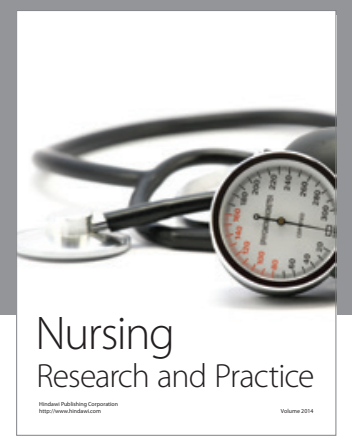

Nursing

Research and Practice

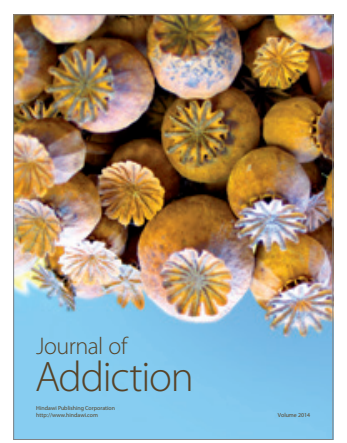

Child Development

Research

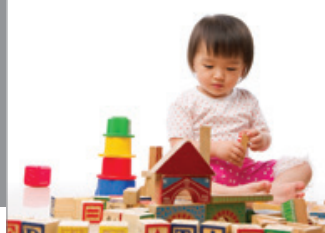

迥
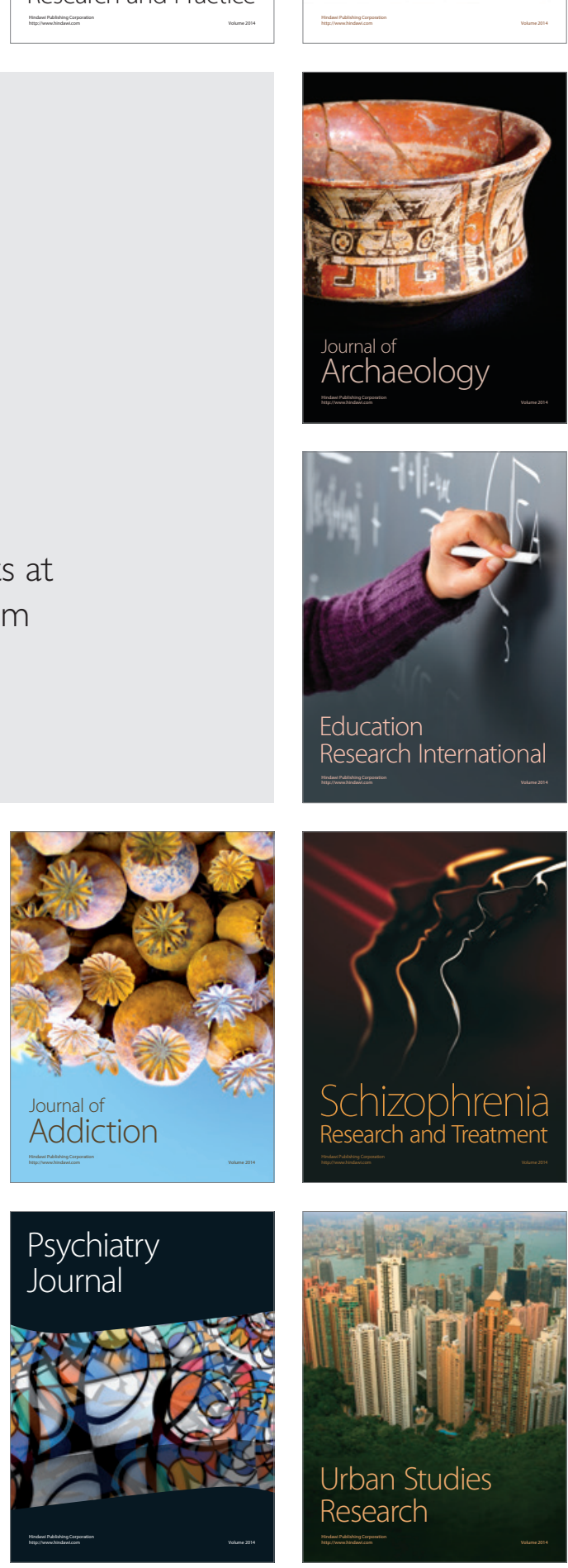